\title{
Digestion susceptibility of seed globulins isolated from different lupin species
}

\author{
Jarosław Czubiński $^{1} \cdot$ Aleksander Siger $^{1} \cdot$ Eleonora Lampart-Szczapa $^{1}$
}

Received: 28 June 2015 / Revised: 2 September 2015 / Accepted: 5 September 2015 / Published online: 7 October 2015

(C) The Author(s) 2015. This article is published with open access at Springerlink.com

\begin{abstract}
The aim of this work was to study the processes taking place during the enzymatic hydrolysis of seed globulins isolated from narrow-leaf (var. Zeus and Bojar) and yellow (var. Lord and Parys) lupin seeds species cultivated in Poland. In lupin seed globulins hydrolysis studies, there were used enzymes typical for the human gastrointestinal tract, such as: pepsin, pancreatin, trypsin and chymotrypsin. The obtained hydrolysates were assessed based on the results of electrophoretic, immunoblotting, as well as chromatographic separations. The evaluation of lupin seed globulins digestion susceptibility was supported by the bioinformatics analyses. Analysis of hydrolysates showed that the proteins present in globulins are completely hydrolysed by: pepsin, double digestion model (pepsin followed by pancreatin) or chymotrypsin. The high specificity of pancreatin and trypsin action results in limited lupin globulins hydrolysis. Protein fraction resistant to the action of these enzymes was $\gamma$-conglutin which also retains its antigenic properties. Its insensitivity to the hydrolysis might be associated with the formation of complexes with flavonoids which were released from other protein connections during digestion, as well as with relatively low number of cleavage sites for trypsin. The analysis of the three-dimensional structure of $\gamma$-conglutin enabled a very accurate description of the amino acid residues localisation, at which trypsin hydrolysis should occur.
\end{abstract}

Jarosław Czubiński

jarczu@up.poznan.pl

1 Department of Biochemistry and Food Analysis, Poznań University of Life Sciences, 28 Wojska Polskiego, 60-637 Poznań, Poland
Keywords Lupin - Digestion susceptibility ·

$\gamma$-Conglutin $\cdot$ Flavonoids-protein complexes $\cdot$ Apigenin $C$-glycosides

\section{Introduction}

Lupin seeds, because of its nutritional and health-promoting properties, have become functional additive used in the manufacture of food products. The main reason for utilising lupin is the fact that seeds of this plant contain a large amount of valuable proteins. Until now, it has been confirmed that the health-promoting properties of lupin seeds are due to the presence of $\gamma$-conglutin. This protein fraction can be effectively used in the treatment of diabetes [1-3]. Based on the exposure of human hepatocyte cell line (HepG2) to $\gamma$-conglutin, it was found that the mechanism of this action is similar to that of insulin in the human body. In addition, other studies have shown that the effect of $\gamma$-conglutin is comparable with known metforminrecognisable antidiabetic medicine. According to Capraro et al. [4], this fraction is able to penetrate into HepG2 cells by pinocytosis and undergoes the multiple phosphorylation after uptake.

The test on animal models showed that the addition of the lupin seed proteins extract to the diet also causes a reduction in blood cholesterol [5]. A mechanism potentially responsible for these health-promoting properties of lupin proteins is associated with the increase in LDL receptor activity. Apart from many benefits arising from the use of lupin seed, as a valuable component of the human diet, there are also risks associated with the occurrence of allergic properties of its proteins. The formation of allergies caused by food allergens, including lupin seed protein, contributes to reducing the health safety of food produced 
with their use. Despite the fact that since 2006, on the basis of the Directive of the European Union 2006/142/EC, lupin has been listed as one of the most important food allergens, detailed information on its proteins allergenic properties is little [6].

Allergenic properties of lupin proteins occurring after ingestion of the seeds of this plant have been first described by Romano et al. [7]. There are also reports of allergic reaction during inhalation and prolonged exposure to this plant [8]. Hypersensitivity to the lupin protein may take the form of: urticaria, rhinitis, mucosal redness, face swelling, coughing and breathing difficulty [8-10]. In extreme cases, for people who are allergic, response was observed as systemic anaphylaxis [11]. Unfortunately, so far the exact dose, the intake of which causes an undesirable symptoms, has not been established [12]. Fæste [12], based on literature data, estimated that this dose may be in the range of 265-1000 mg of lupin seed proteins. The main protein binding $\operatorname{IgE}$ of allergic characterised by molecular weights in the range of: $45-42 \mathrm{kDa}[10,13,14]$. Other potential allergens may be a protein with the molecular weight of $13 \mathrm{kDa}$ [10], $29 \mathrm{kDa}$ [15], $34 \mathrm{kDa}$ [16], $38 \mathrm{kDa}$ [12] and $66 \mathrm{kDa}$ [17].

The large heterogeneity of lupin proteins that exhibit antigenic properties makes allergy a problem that requires intensive and detailed analysis. So far, amino acid sequence of lupin seeds proteins that are responsible for allergies has not been identified. A serious threat to health in the case of food allergies are cross-reactions that occur most frequently within the same family. In the case of lupin, the most frequently observed cross-reaction is the one with peanut $[9,10,18]$. The main proteins that cause allergic reactions in patients with known allergies to peanuts are these included in the $\alpha$ - and $\beta$-conglutin fractions [19-21]. Ballabio et al. [22] analysing the allergic reaction in twelve patients with allergy to peanuts found that seven of them reacted positively to $\beta$-conglutin. Other conglutin fraction exhibited weaker allergic reactions: $\gamma$-conglutin (in four out of twelve patients), $\alpha$-conglutin (in five of twelve patients) and $\delta$-conglutin (in three out of twelve patients) [22].

Lupin seed proteins during heat treatment change their antigenic properties. Álvarez-Álvarez et al. [15] analysed the influence of extrusion cooking, autoclaving and microwave heating on the stability of lupin seed proteins. On the basis of the immunoblotting analysis, they found that only the autoclaving process causes a significant change in the amount of proteins that interact with the antibodies of people who were allergic to lupin. The autoclaving process, which runs for $20 \mathrm{~min}$, causes that only proteins with molecular weights of 29 and $23 \mathrm{kDa}$ bind IgE antibodies. Extending the autoclaving process to $10 \mathrm{~min}$ resulted in the disappearance of the above-mentioned immunoreactive protein bands on the immunoblotting membrane. However, longer autoclaving process contributed to the appearance of the new protein band interacting with IgE antibodies, characterised by a molecular weight of $70 \mathrm{kDa}$.

Food products containing lupin seeds after intake are subjected to complex processes of digestion. Some of its components are hydrolysed, while others remain in an unchanged form. To the best of our knowledge, there are limited data concerning susceptibility of lupin seed globulins to enzymatic hydrolysis. The presence of digestion insensitive proteins, as well as formation of peptides, may result in the occurrence of allergic reaction in people sensitised to lupin. Therefore, the aim of the presented study was to characterise digestion processes of seed globulins isolated from different lupin species. Those characteristics included estimation of allergenic properties of proteins which remain after digestion.

\section{Materials and methods}

\section{Reagents}

Pepsin from the porcine gastric mucosa (P7000, activity $\geq 250$ units $/ \mathrm{mg}$ protein), pancreatin from the porcine pancreas (P1750, activity equivalent to $4 \times$ U.S.P. specifications), trypsin from the porcine pancreas, TPCK treated in order to prevent any chymotrypsin activity (T1426, $\geq 10,000$ units/mg protein), chymotrypsin from the porcine pancreas (C4120, $\geq 40$ units/mg protein), Tris(hydroxymethyl) aminomethane, sodium dodecyl sulphate (SDS), $\mathrm{N}, \mathrm{N}, \mathrm{N}^{\prime}, \mathrm{N}^{\prime}$-tetramethylethylenediamine (TEMED), trifluoroacetic acid (TFA), glycine, acrylamide, nitroblue tetrazolium (NBT), 5-bromo-4-chloro-3-indolyl phosphate (BCIP), bovine serum albumin (BSA), antirabbit IgG-alkaline phosphatase antibodies and Coomassie Brilliant Blue R-250 were purchased from Sigma-Aldrich (St. Louis, MO, USA). Rabbit IgG polyclonal antibodies specific to yellow lupin (Lupinus luteus) $\gamma$-conglutin were obtained from Agrisera (AS08335, Vännas, Sweden). Acetonitrile (HPLC-grade) was obtained from Merck (Darmstadt, Germany). All other solvents and chemicals used in this study were of analytical grade. Redistilled water purified via the Milli-Q system (Millipore, Bedford, USA) was used during the HPLC analysis.

\section{Materials}

Narrow-leaf (L. angustifolius, var. Zeus and Bojar) and yellow (L. luteus, var. Lord and Parys) low-alkaloid lupin seeds were obtained from the Plant Breeding Station Smolice, Przebędowo branch, Poland (harvested in 2011). All samples were milled with an IKA M20 universal laboratory 
mill (IKA-Werke GmbH\&Co, Staufen, Germany), sieved to obtain a fraction below $1.6 \mathrm{~mm}$ and stored in closed polyethylene bags at $-18{ }^{\circ} \mathrm{C}$ until the analysis.

\section{Lupin seed globulins extraction}

Prior protein extraction all samples were defatted for $2 \mathrm{~h}$ using an automatic Soxhlet Bühi Extraction System B-811 (Bühi Labortechnik AG, Flawil, Switzerland) with $n$-hexane as a solvent. Extraction of lupin seed globulins was carried out using the method proposed by Czubinski et al. [23]. Briefly, albumins were removed from defatted lupin flour using extraction with water $\mathrm{pH} 8.0$ containing $10 \mathrm{mM}$ $\mathrm{CaCl}_{2}, 10 \mathrm{mM} \mathrm{MgCl}_{2}$ (34 ml per $1 \mathrm{~g}$ of lupin flour) for $4 \mathrm{~h}$. Then samples were centrifuged for $1 \mathrm{~h}$ at $20,000 \mathrm{~g}$, and the pellet devoid of albumin was used for further extraction. Globulins extraction was performed by 4-h elution using $0.1 \mathrm{M}$ Tris- $\mathrm{HCl} \mathrm{pH} 7.5$ buffer containing $10 \% \mathrm{NaCl}(\mathrm{w} / \mathrm{v})$, $\mathrm{Na}_{3} \mathrm{~N} 0.05 \%$ (w/v) (34 ml per $1 \mathrm{~g}$ of lupin flour). Then samples were centrifuged for $1 \mathrm{~h}$ at $20,000 \mathrm{~g}$, and proteins were precipitated from the supernatant by adding ammonium sulphate $(561 \mathrm{~g} / \mathrm{l})$. Salting was carried out for $30 \mathrm{~min}$, and then samples were centrifuged for $20 \mathrm{~min}$ at $20,000 \mathrm{~g}$. The precipitate containing salted globulins was resuspended in $50 \mathrm{mM}$ Tris- $\mathrm{HCl} \mathrm{pH} 7.5$ buffer $(5.7 \mathrm{ml}$ per $1 \mathrm{~g}$ of lupin flour). All stages of protein extraction from defatted lupin flour were performed at $4{ }^{\circ} \mathrm{C}$ with constant mechanical stirring. The obtained lupin globulins extract was filtered through $0.45 \mu \mathrm{m}$ PVDF syringe filter (Millipore, Bedford, USA) and desalted using automatic FPLC system with the HiTrap desalting column (GE Healthcare, Uppsala, Sweden) equilibrated with $50 \mathrm{mM}$ Tris- $\mathrm{HCl}$ buffer at $\mathrm{pH}$ 7.5. Desalted proteins were collected in $2 \mathrm{ml}$ fractions and stored at $-18{ }^{\circ} \mathrm{C}$ until future analysis.

\section{Protein concentration measurements}

Protein concentration was determined by colorimetric Bradford method [24]. Analyses were carried out at wavelength $\lambda=595 \mathrm{~nm}$ (UV-Vis spectrophotometer SP 8001, Metertech Inc. Taipei, Taiwan). To determine protein concentration, standard curve based on BSA has been made $\left(y=0.6192 x ; R^{2}=0.9966\right)$.

\section{Enzymatic digestion of lupin seed globulins in the model system}

Digestion of lupin seed globulins was carried out applying the method described previously [23, 25]. Firstly, three different combinations of proteolytic enzymes were used in the first stage: pepsin, pancreatin and double digestion model where pepsin followed by pancreatin were used. In the next stage, additionally trypsin and chymotrypsin were used in order to evaluate detailed digestion, which takes place when pancreatin was used. Briefly, for pepsin digestion lupin seed globulins were resuspended in water to the final concentration of $1 \mathrm{mg}$ per $\mathrm{ml}$ and adjusted to pH 2 with $0.1 \mathrm{M} \mathrm{HCl}$, and the enzyme solution $(1 \mathrm{mg} /$ $\mathrm{ml}$ in water) was added in the ratio of 1:30 enzyme/lupin seed globulins $(\mathrm{v} / \mathrm{v})$. The sample was incubated for $1 \mathrm{~h}$ at $37{ }^{\circ} \mathrm{C}$ under gentle stirring. The reaction was stopped by changing $\mathrm{pH}$ to 7.5 by adding $0.1 \mathrm{M} \mathrm{NaOH}$. For pancreatin, trypsin and chymotrypsin treatment lupin seed globulins were resuspended in water to final concentration of $1 \mathrm{mg}$ per $\mathrm{ml}$ and adjusted to the $\mathrm{pH} 7.5$ with $0.1 \mathrm{M} \mathrm{NaHCO}_{3}$, and enzyme solution $(1 \mathrm{mg} / \mathrm{ml}$ in water) was added in the ratio of 1:30 enzyme/lupin globulins (w/w). The sample was incubated for $1 \mathrm{~h}$ at $37{ }^{\circ} \mathrm{C}$ under gentle stirring. The reaction was stopped by changing $\mathrm{pH}$ to 2 by adding $0.1 \mathrm{M}$ $\mathrm{HCl}$. Combination of pepsin and pancreatin digestion (the double digestion model) was performed in such a way that the pepsin treatment sample was brought to $\mathrm{pH} 7.5$ and then pancreatin was added.

\section{Sodium dodecyl sulphate-polyacrylamide gel electrophoresis (SDS-PAGE)}

SDS-PAGE electrophoresis of lupin seed globulins as well as products of their enzymatic hydrolysis was carried out according to the method proposed by Laemmli [26] using $12.5 \%$ polyacrylamide gel. Polypeptide bands were stained in Coomassie Brilliant Blue G-250 (Sigma-Aldrich, St. Louis, MO) for $12 \mathrm{~h}$. Relative molecular masses of protein were determined by a comparison to the molecular weight marker (Feremntas, Lithuania).

\section{Reverse-phase liquid chromatography of peptides (RP-HPLC)}

RP-HPLC analyses were prepared by separation of digested lupin seed globulins on reversed-phase high-performance liquid chromatography (HPLC 600 Pump and Controller-Waters, Milford, MA, USA) on XBridge BEH300 C18 $(4.6 \times 250 \mathrm{~mm}, 5 \mu \mathrm{m})$ (Waters, Milford, MA, USA) column, equilibrated with solvent $\mathrm{A}\left(\mathrm{H}_{2} \mathrm{O}\right.$ containing $0.5 \%$ formic acid, v/v). Gradient elution was performed by adding solvent B (acetonitrile) up to $75 \%$ in $65 \mathrm{~min}$. The flow rate was $1.0 \mathrm{ml} / \mathrm{min}$. The injection volume was $25 \mu \mathrm{l}$, while the column temperature was maintained at $25{ }^{\circ} \mathrm{C}$. Signal was monitored at 200-600 $\mathrm{nm}$ with the diode array detector (PDA detector 2998 Waters, Milford, MA, USA).

\section{$\gamma$-Conglutin purification}

$\gamma$-Conglutin was purified from lupin seed globulins in order to utilise this protein fraction during 
immunoblotting. Purification protocol included separation of desalted lupin seed globulin by anion and cation exchange chromatography as it was previously described $[25,27]$. Firstly, desalted lupin seed globulins were subjected on HiTrap Q column (GE Healthcare, Uppsala, Sweden) equilibrated with $50 \mathrm{mM}$ Tris- $\mathrm{HCl} \mathrm{pH}$ 7.5 buffer. Under these conditions, $\gamma$-conglutin was not adsorbed on the column media. Fractions containing $\gamma$-conglutin were collected and concentrated on $30 \mathrm{kDa}$ molecular weight cutoff Amcion centrifugal filters (Millipore, Bedford, USA). Secondly, cation exchange purification was run by subjecting concentrated $\gamma$-conglutin on HiTrap SP column (GE Healthcare, Uppsala, Sweden) and separation in linear gradient of $\mathrm{NaCl}$ from 0 to $1 \mathrm{M}$ was carried out. Finally, $\gamma$-conglutin fractions were concentrated on $10 \mathrm{kDa}$ molecular weight cutoff Amcion centrifugal filters (Millipore, Bedford, USA) and used as a standard in immunoblotting.

\section{Immunoblotting}

Firstly, SDS-PAGE-separated lupin seed globulins were transferred from the gel onto a $0.45-\mathrm{mm}$ PVDF membrane Immobilon-P on a semi-dry electrophoretic transfer cell TRP-77 (GE Healthcare, Uppsala, Sweden). The membrane was pre-activated by sequentially immersing in: methanol (1 min), distilled water (5 min) and $20 \mathrm{mM}$ Tris, pH 8.3 buffer containing $192 \mathrm{mM}$ glycine and $20 \%$ methanol (10 $\mathrm{min})$. The transfer was conducted at a constant current of $0.6 \mathrm{~mA} / \mathrm{cm}^{2}$ of the membrane for $1 \mathrm{~h}$. Secondly, the membrane was incubated for $12 \mathrm{~h}$ at $4{ }^{\circ} \mathrm{C}$ in a Tris buffer (10 mM Tris- $\mathrm{HCl} \mathrm{pH} 7.5,150 \mathrm{mM} \mathrm{NaCl})$ containing $2 \% \mathrm{BSA}$. After blocking, the membrane was washed three times with $10 \mathrm{mM}$ Tris- $\mathrm{HCl} \mathrm{pH} 7.5$ containing $150 \mathrm{mM} \mathrm{NaCl}$ and $0.05 \%$ Tween $20(\mathrm{v} / \mathrm{v})$. The membrane was then soaked for $2 \mathrm{~h}$ with the primary antibody (rabbit polyclonal $\operatorname{IgG}$ antibody) specific for the L. luteus $\gamma$-conglutin (Agriser, Vännas, Sweden) in a ratio of 1000:1 (v/v). The antigen-IgG complexes were detected by 1-h incubation with the secondary antibody (goat polyclonal antibody directed against the rabbit $\operatorname{IgG})$. The secondary antibody was diluted 30,000:1. Due to the fact that the secondary antibody was conjugated with alkaline phosphatase, the membrane was transferred to $100 \mathrm{mM}$ Tris- $\mathrm{HCl} \mathrm{pH} 9.5$ buffer containing $100 \mathrm{mM}$ $\mathrm{NaCl}$ and $5 \mathrm{mM} \mathrm{MgCl}_{2}$. Finally, the membrane was incubated with alkaline phosphatase substrate. The substrate consisted of NBT $(3 \mathrm{mg} / \mathrm{ml})$ and BCIP $(1.5 \mathrm{mg} / \mathrm{ml})$. The reaction was stopped by rinsing the membrane with distilled water. The dried membrane was scanned and compared with the electrophoretic gel obtained for the analysed samples.

\section{Bioinformatics analyses}

Conglutin fraction sequences deposited in NCBI (http:// www.ncbi.nlm.nih.gov/) were used in order to theoretical analysis digestion susceptibility. Digestion susceptibility was assayed with ExPASy PeptideCutter tool [28]. The $\gamma$-conglutin (PDB accession number: $4 \mathrm{pph}$, protomer: A) secondary structure elements were assignment based on the DSSP algorithm [29]. The protein structure figure was prepared with PyMOL (http://www.pymol.org/).

\section{Results and discussion}

\section{Lupin seed globulins enzymatic hydrolysis susceptibility}

Products introduced into the human body are subjected to a complex process of digestion, during which some components are digested, while others remain in an unchanged form. Due to potentially allergenic effects of lupin proteins, information about effectiveness of proteolytic enzymes hydrolysis may have practical application importance, e.g. in preparation of hypoallergenic lupin products. In this study for hydrolysis efficiency, the following enzymes were used: pepsin, pancreatin and the double digestion model (pepsin and pancreatin). Our previous results provided information about $\gamma$-conglutin insensitivity to pancreatin action; therefore, in hydrolysis analysis trypsin and chymotrypsin were also utilised.

Lupin seed globulins digestibility to pepsin, pancreatin and the double digestion system action was examined on the basis of SDS-PAGE electrophoretic separation (Fig. 1). In order to determine which proteins were digested, crude lupin seed globulins extracts were also analysed (Fig. 1, lane 1). A strong resemblance of globulins profiles within the varieties of the same lupin seed species was proved. Narrow-leaf lupin seed globulins profiles were characterised by the presence of proteins with molecular weights in the range of $68-50 \mathrm{kDa}$ (Fig. 1, lane 1). Similarly, yellow lupin seed globulins contained manly proteins with molecular weights in the range of 66-48 kDa (Fig. 1, lane 1). The hydrolysis with pepsin and the double digestion model (pepsin followed by pancreatin) leads to the disappearance of protein bands on SDS-PAGE gels (Fig. 1, lanes 2, 4). The observed lack of protein bands is related to the fact that peptides caused by pepsin activity were not visible under the conditions of electrophoretic separation. This fact indicates that lupin seed globulins are susceptible to proteolysis conducted by these enzymes. Hydrolysis conducted by pancreatin, which was used in the double digestion model, caused further degradation of the peptides formed in the first step (pepsin action). 


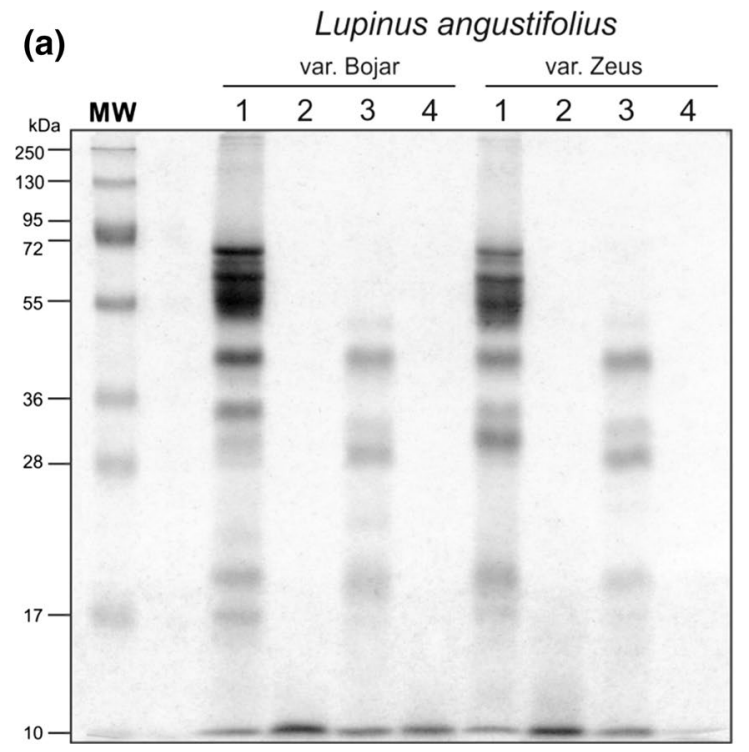

Fig. 1 SDS-PAGE separations profiles of lupin seed globulins and their hydrolysis products. a Electrophoretic profile of narrow-leaf ( $L$. angustifolius) and b yellow (L. luteus) lupin seed samples: 1 lupin

In case of pancreatin hydrolysates, disappearance of protein bands corresponding to the molecular weight in the range of $68-50 \mathrm{kDa}$ (L. angustifolius) and $66-48 \mathrm{kDa}$ (L. luteus) was observed (Fig. 1, lane 3). Proteins characterised by such molecular weights belong to the $\alpha$ - and $\beta$-conglutin fractions [30]. These fractions act as storage proteins in the lupin seed and constitute up to $90 \%$ of all globulins [30, 31]. In all pancreatin hydrolysed samples, bands corresponding to proteins with molecular weights of 31.4 and $16.5 \mathrm{kDa}$ were observed (Fig. 1, lane 3). In narrow-leaf lupin seed globulins samples digested by pancreatin, an additional protein band with the molecular weight of $46 \mathrm{kDa}$ was found (Fig. 1a, lane 3). Protein bands of these molecular weights correspond to $\gamma$-conglutin $\alpha$ $(31.4 \mathrm{kDa})$ and $\beta(16.5 \mathrm{kDa})$ subunits $[23,25,27]$. The protein band with a molecular weight of $46 \mathrm{kDa}$ corresponds to not-reduced form of $\gamma$-conglutin (coupled $\alpha$ and $\beta$ subunits) [27]. Observations regarding narrow-leaf and yellow lupin seed $\gamma$-conglutin resistance to pancreatin hydrolysis are similar to these found for white lupin seed ( $L$. albus) $\gamma$-conglutin [32]. The characteristics of the products obtained by enzymatic digestion of lupin seed globulins were also carried out by liquid chromatography in reversephase mode (RP-HPLC) (Figs. 2, 3). In these analyses, a column containing a silica modified octadecyl carbon chains (C18) media was used. In the RP-HPLC separations, compounds adsorbed on the $\mathrm{C} 18$ media of the column elute in accordance with their increased hydrophobicity [33]. Because of the strong interaction of hydrophobic compounds to the $\mathrm{C} 18$ media, this type of column is dedicated

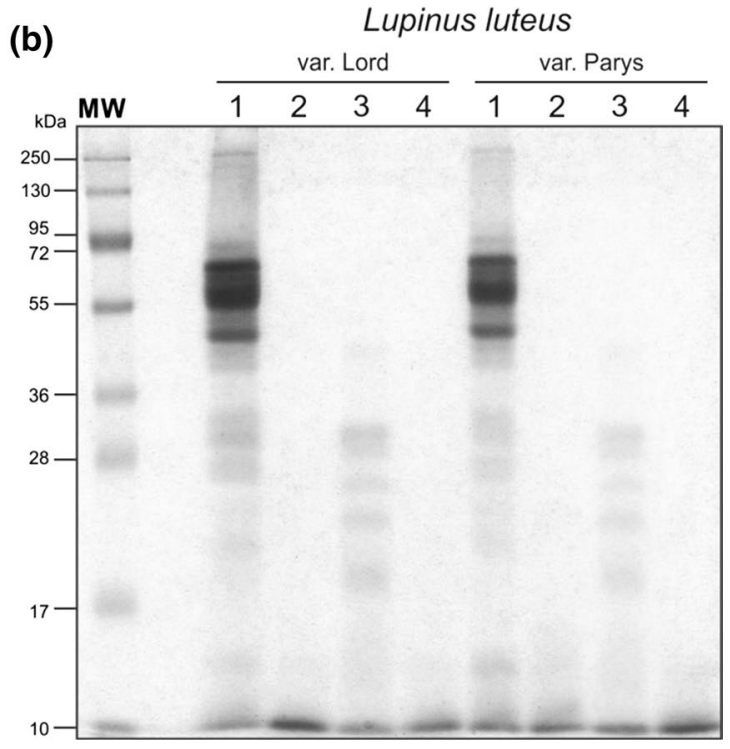

seed globulins, 2 pepsin hydrolysate, 3 pancreatin hydrolysate and 4 products of the double digestion model (pepsin and pancreatin). $M W$ molecular weight marker

only to the separation of short peptides. Therefore, in these studies, separation of crude lupin seed globulins was not carried out.

The obtained results were presented as the chromatograms recorded at the wavelength typical of the absorption of the peptide bond $\lambda=214 \mathrm{~nm}$ (Fig. 2). Numerous peptides constituted characteristic profiles, which differed depending on the enzymes used to digest lupin seed globulins. In case of hydrolysis carried out by pepsin, the presence of large amounts of peptides characterised by the retention times of 5-55 min was reported (Fig. 2a, b). Peptide profiles, obtained after pepsin digestion, were different among the analysed species of lupin seeds, as well as among the studied varieties within species. The observed differences might be the result of a wide proteolytic specificity of pepsin [34]. A large number of generated peptides confirm previous observations concerning the susceptibility of lupin seed globulins to hydrolysis carried out by pepsin (Fig. 1, lane 2). Similar RP-HPLC peptide profiles were found for lupin seed globulins hydrolysed by pancreatin. Most of the peptides present in these samples eluted from the column within 5-15 min (Fig. 2c, d). These retention times were shorter than in case when pepsin was used for hydrolysis. High similarity of peptide profiles may be due to the fact that within pancreatin the main protease is trypsin [35]. This enzyme has well-defined specificity, therefore only homologous proteins can be hydrolysed, and resulting peptides have similar amino acid composition [34]. As a result, such peptides are characterised by identical retention times during RP-HPLC chromatographic 

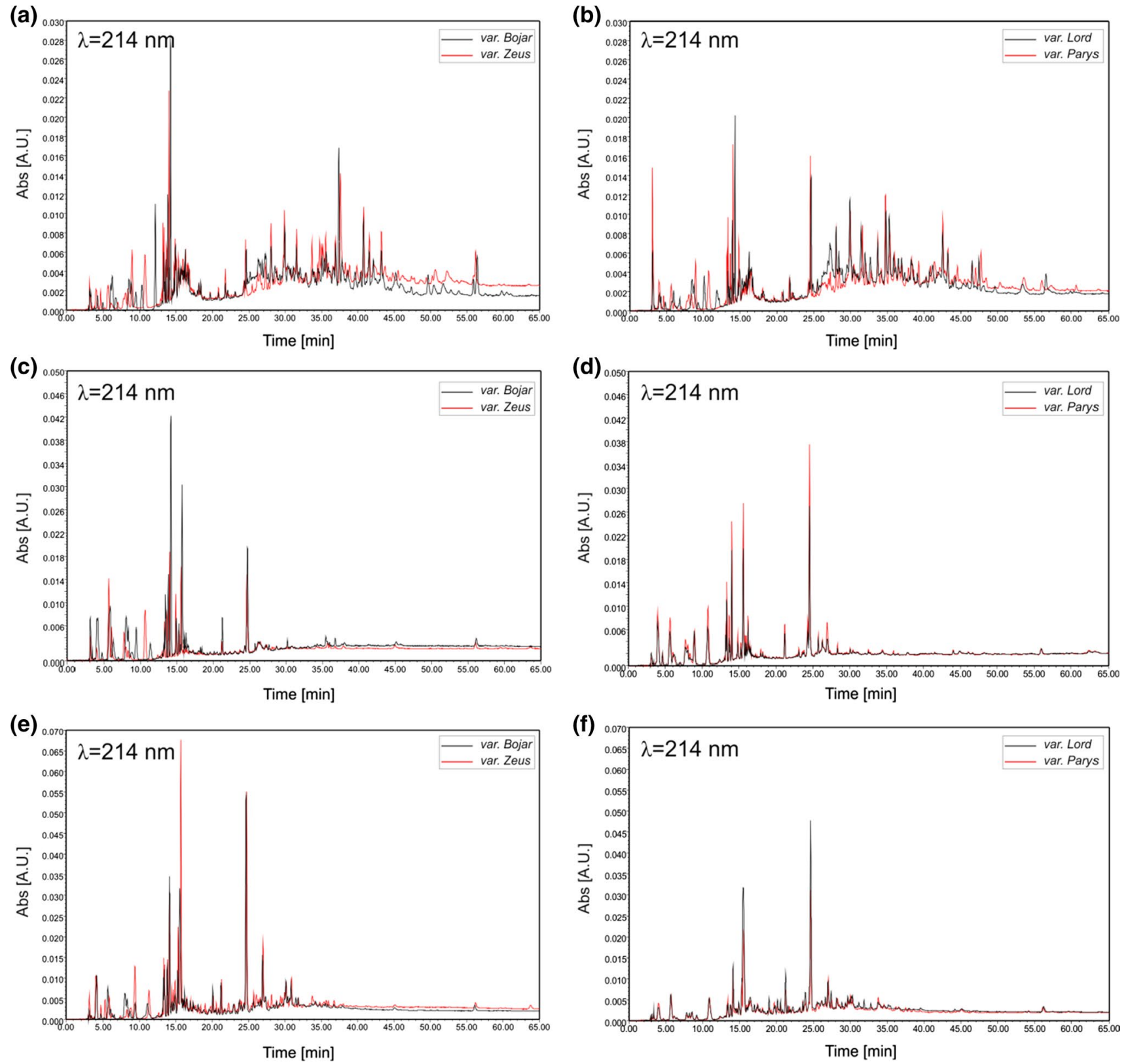

Fig. 2 Reverse-phase (RP-HPLC) chromatograms obtained by separations of lupin seed globulins samples after hydrolysis by: $(\mathbf{a}, \mathbf{b})$ pepsin $(\mathbf{c}, \mathbf{d})$ and pancreatin $(\mathbf{e}, \mathbf{f})$ in the double digestion model (pep-

separations (Fig. 2c, d). Lupin seed globulins digestion in the double digestion model resulted in the formation of a number of new peptides (Fig. 2e, f). These peptide profiles differ from these previously observed (Fig. 2a-d) and were related to the fact that pancreatin caused subsequent hydrolysis of peptides generated in first step of digestion. The profile obtained after pepsin digestion was characterised by the presence of peptides with retention times in the range of 5-55 min (Fig. 2a, b). The peptides present in the samples, where the additional pancreatin was used for digestion, were characterised by the retention times in the

sin and pancreatin). Chromatographic separations were monitored at the wavelength $\lambda=214 \mathrm{~nm}$ (detection of peptide bond)

range of 5-35 min (Fig. 2e, f). The subsequent hydrolysis caused the presence of new, shorter peptides, which were characterised by lower hydrophobicity. The change in hydrophobicity of peptides explains their faster retention times in double digestion model (within $35 \mathrm{~min}$ ).

It is worth highlighting that in all peptide profiles the compounds characterised by the retention time of $24 \mathrm{~min}$ were presented (Figs. 3, 4). The contents of these compounds varied depending on the enzyme used for the hydrolysis. The UV absorption maxima of these compounds were at wavelengths $\lambda=270$ and $\lambda=335 \mathrm{~nm}$, 
(a)

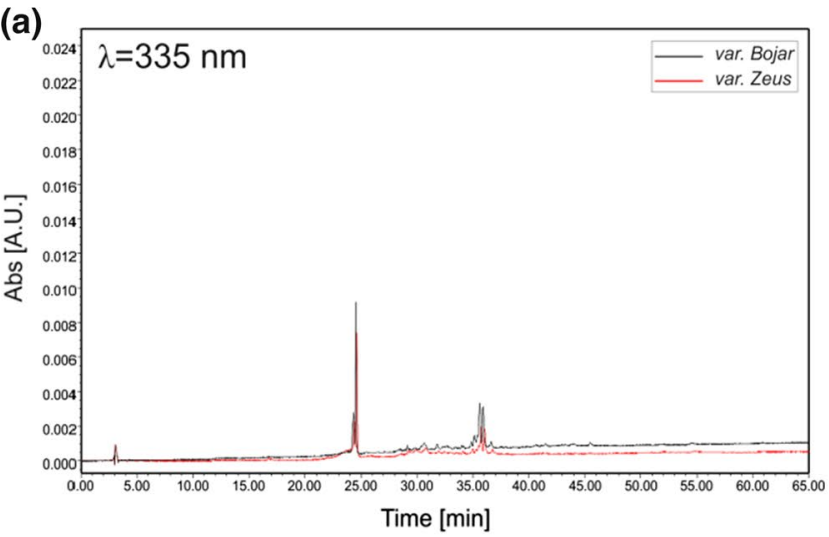

(c)

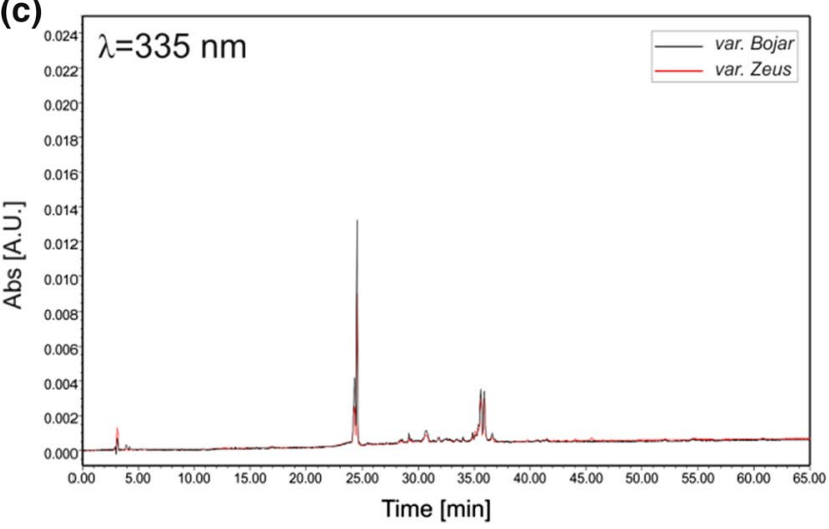

(e)

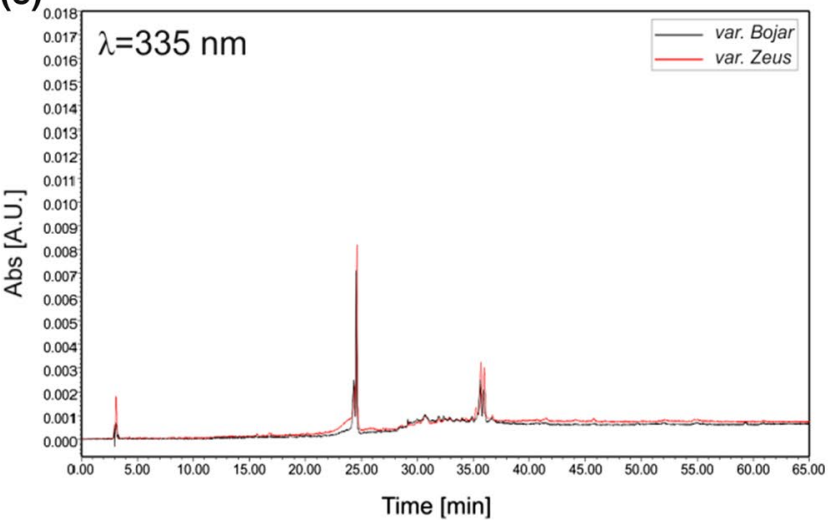

Fig. 3 Reverse-phase (RP-HPLC) chromatograms obtained by separations of lupin seed globulins samples after hydrolysis by: $(\mathbf{a}, \mathbf{b})$ pepsin $(\mathbf{c}, \mathbf{d})$ and pancreatin $(\mathbf{e}, \mathbf{f})$ in the double digestion model (pep-

suggesting that they belong to flavonoids (Fig. 4b, peaks 1, 2 and 3). Such flavonoids (apigenin derivatives) relisted from narrow-leaf seed globulins during digestion were identified in our previous research [23].

\section{Phenolic compounds and their interaction with lupin seed globulins}

Flavonoids are natural low molecular weight plant metabolites which are classified as natural antioxidants. The
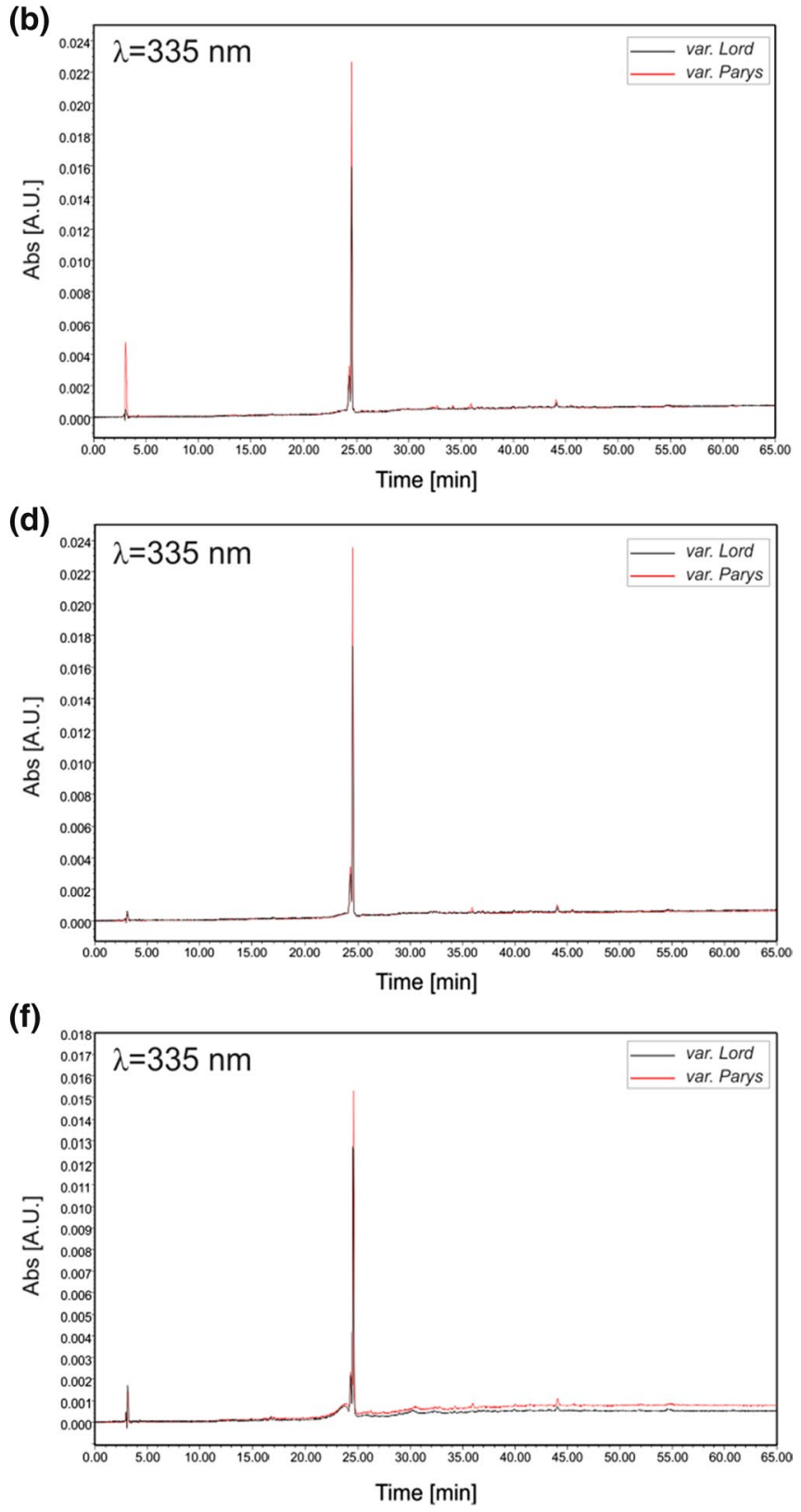

sin and pancreatin). Chromatographic separations were monitored at the wavelength $\lambda=335 \mathrm{~nm}$ (detection of flavonoids)

presence of these compounds in lupin seeds has been confirmed in many studies [36-39]. Each time before hydrolysis, lupin seed globulins were subjected to desalting using a Sephadex G-25 media-filled column (GE Healthcare, Sweden). During this process, all particles of less than $5 \mathrm{kDa}$ are removed (http://www.gelifesciences.com, HiTrap Desalting Columns); therefore, the presence of these compounds in hydrolysates is due to formation of proteins-flavonoids complexes. Figures 3 and 4a present RP-HPLC chromatographic separations of lupin seed globulins hydrolysed 
(a)

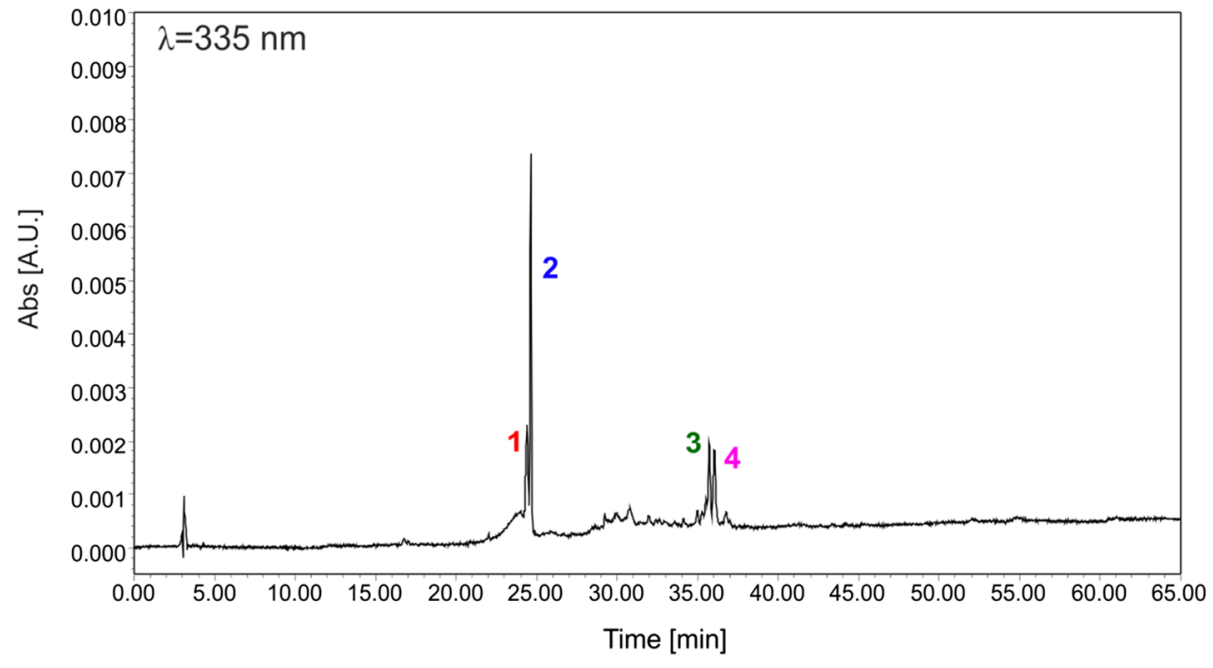

(b)
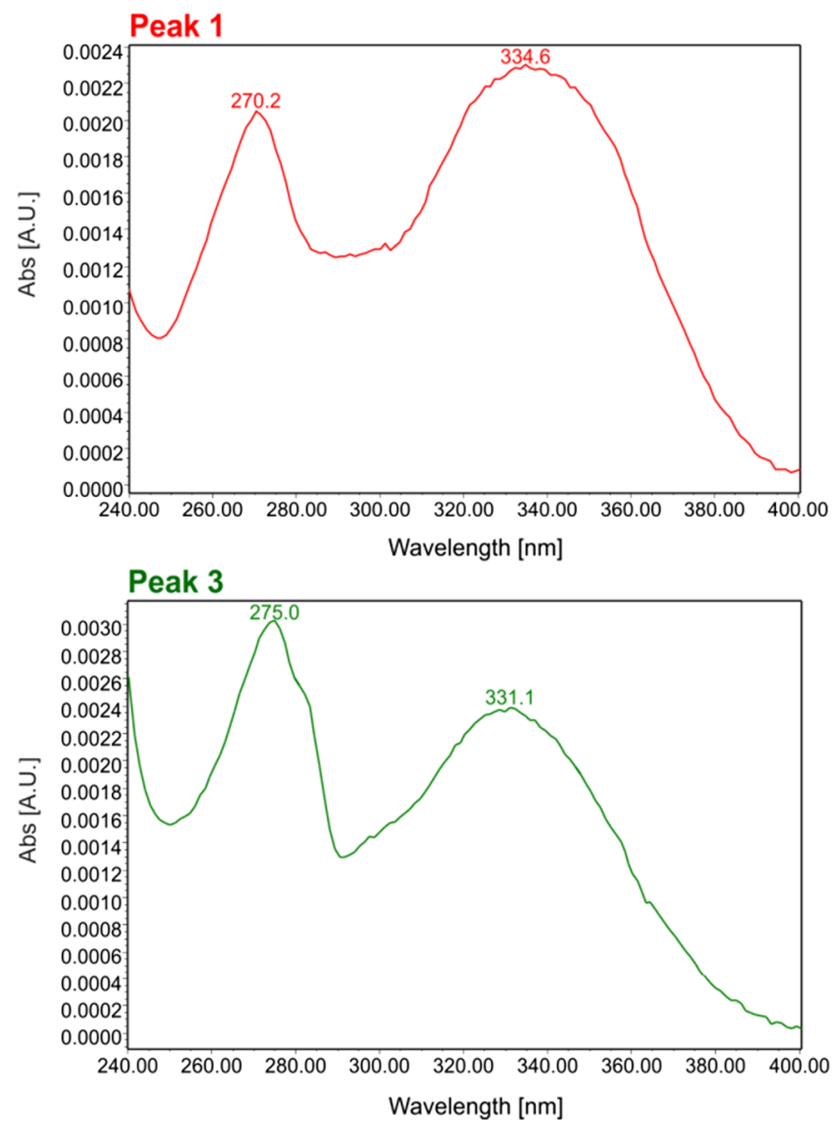

Fig. 4 Detection of phenolic compounds in lupin seed globulins hydrolysate. a The reverse-phase (RP-HPLC) chromatogram obtained by separations of narrow-leaf ( $L$. angustifolius) lupin seed globu-

samples. Separations were monitored at $\lambda=335 \mathrm{~nm}$ wavelength which is typical for detection of phenolic compound. In case of yellow lupin samples, only two phenolic compounds which eluted at 24 min were detected (Fig. 3b, $\mathrm{d}, \mathrm{f}$ ). Figure $4 \mathrm{~b}$ (peaks 1 and 2) presents the UV spectra of these compounds which were identical with previously
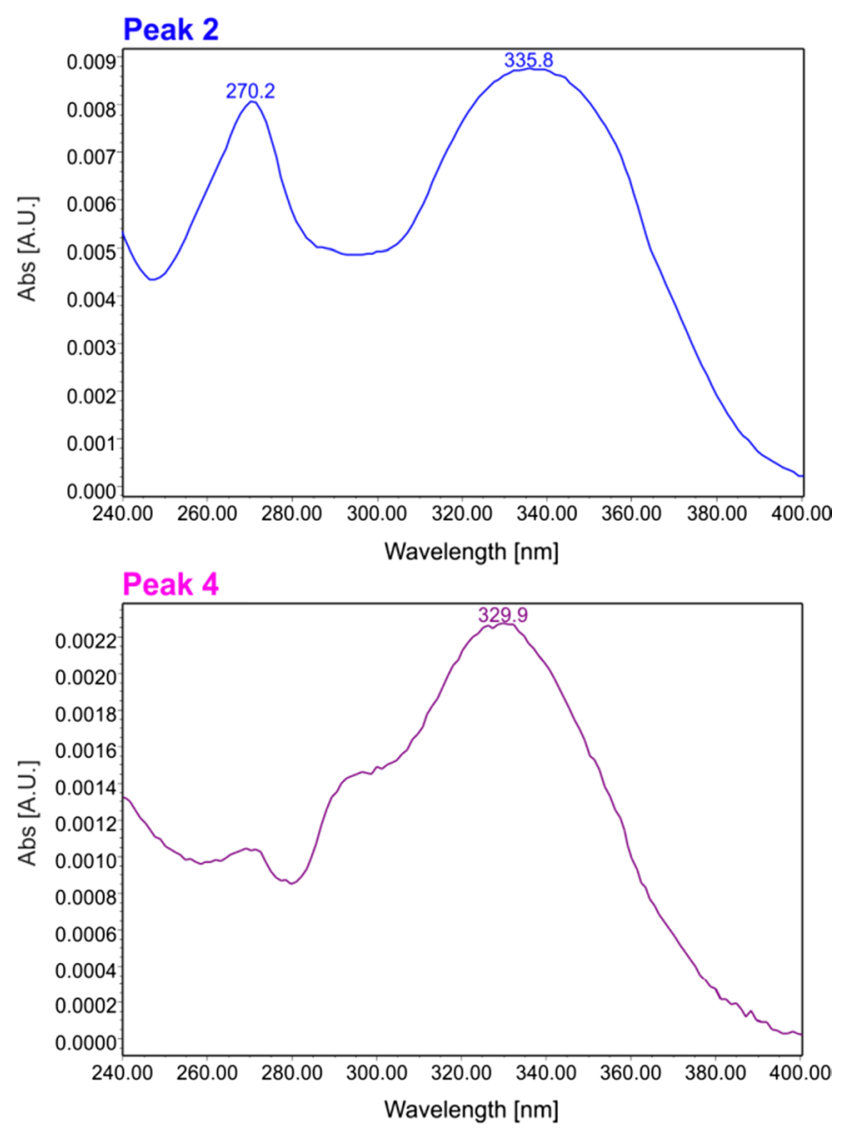

lins samples after pepsin hydrolysis (monitored at the wavelength $\lambda=335 \mathrm{~nm}$ ). $\mathbf{b}$ UV spectra of phenolic compound present in narrowleaf (L. angustifolius) lupin seed globulins pepsin hydrolysate

detected apigenin derivatives [23, 39]. Domain phenolic compounds present in economically important lupin seeds species (narrow-leaf, yellow and white) are apigenin derivatives [39]. These compounds were identified as apigenin-6,8-di- $C$ - $\beta$-glucopyranoside and apigenin-7- $O-\beta$ apiofuranosyl-6,8-di- $C-\beta$-glycopyranoside. Their content 
was varied primarily depending on the analysed species. The content of apigenin- 6,8 -di- $C$ - $\beta$-glucopyranoside was highest in the seeds of yellow lupin and ranged from 53.63 to $63.14 \mathrm{mg} / 100 \mathrm{~g}$ d.m., while the lowest content was noted in case of white lupin seeds (11.90-14.30 mg/100 g d.m.). A similar dependency was found for the second apigenin derivative. The content of apigenin-7- $O$ - $\beta$-apiofuranosyl6,8 -di- $C$ - $\beta$-glycopyranoside ranged from $25.75 \mathrm{mg} / 100 \mathrm{~g}$ d.m. (white lupin seeds) to $87.69 \mathrm{mg} / 100 \mathrm{~g} \mathrm{~d} . \mathrm{m}$. (yellow lupin seeds) [39]. The content of phenolic acids in lupin seeds depends also on the analysed species. The highest content of phenolic acids was determined in the yellow lupin seed variety Parys ( $82.06 \mathrm{mg} / \mathrm{kg} \mathrm{d.m}$.) [39]. Seeds of white lupin variety Butane were characterised by the lowest content of phenolic acids $(39.96 \mathrm{mg} / \mathrm{kg} \mathrm{d}$.m.). The content of individual phenolic acids also varied between analysed lupin seed species. $p$-Hydroxybenzoic acid derivatives were domain phenolic acids in both analysed narrow-leaf lupin seed varieties, while yellow lupin seed contained mainly cinnamic acid derivatives [39].

All analysed hydrolysates contain the two apigenin derivatives (apigenin-6,8-di- $C$ - $\beta$-glucopyranoside and apigenin-7-O- $\beta$-apiofuranosyl- 6,8 -di- $C$ - $\beta$-glycopyranoside) which were characterised by the 24-min retention time (Fig. 3). Additionally, narrow-leaf lupin seed varieties contain also two unidentified compounds which eluted about 35 min. (Figure 3a, c, e). The characteristic UV spectra of all phenolic compound present in lupin hydrolysates are presented in Fig. 4b. Two of them had characteristic maximum of absorbance at $\lambda=270$ and $\lambda=335 \mathrm{~nm}$, and as mentioned before they are lupin seed apigenin derivatives $[23,39]$. The third compound had similar maximum of absorbance to apigenin derivatives $(\lambda=275$ and $\lambda=331 \mathrm{~nm}$ ) which indicated that this compound is also flavone. Longer retention time of this compound compared to the previously identified apigenin derivatives might indicate that the third compound could be free aglycone. The fourth compound was characterised by maximum of absorbance at $\lambda=329 \mathrm{~nm}$. Such a maximum of absorbance is typical for cinnamic acid derivatives, particularly ferulic acid. Dueñas al. [38] studied phenolic compound content in lupin seed during germination. These authors determined variable composition and content of free and conjugated forms of isoflavones, flavones, dihydroflavonols and such phenolic acids as: ferulic acid and trans- $p$-coumaryl glutaric acid. Additionally, according to Siger et al. [39], lupin seeds demonstrate also the presence of caffeic and $p$-coumaric acids.

Interactions between phenolic compound and proteins can be considered in two aspects. Firstly, phenolic compounds cause changes in the physicochemical properties of proteins. The formation of such complexes may lead to lowering the nutritional value of proteins by changing of their solubility, thermal stability and digestibility [40, 41]. Secondly, the fact of proteins complexes formation may substantially reduce the health-promoting potential of phenolic compounds by masking of their antioxidant properties [41, 42]. Our previous study indicated possibility of formation of the static complex between $\gamma$-conglutin and vitexin with a binding constants $\left(K_{\mathrm{a}}\right)$ and a number of binding places $(n)$ of $3.47 \times 10^{4} \mathrm{M}^{-1}$ and 1.017 , respectively [25]. Such a protein-flavonoid complex might affect digestion susceptibility of $\gamma$-conglutin, which was observed in the presented study (Fig. 1, line 3).

\section{Immunoreactive properties of digested lupin seed globulins}

The growing interest in the use of lupin, as a valuable component of food is limited by the occurrence of hypersensitivity to allergic proteins of its seeds [42, 43]. The problem has become so significant that the Parliament of the European Union in Directive 2006/142/EC mentioned lupin among 14 major food allergens which are responsible for $90 \%$ of food allergies [6]. Due to the importance of lupin seed globulins immunoreactivity, in this study we evaluated the antigenic properties of obtained hydrolysates. The method of immunoblotting utilising rabbit polyclonal IgG antibody specific to yellow lupin $\gamma$-conglutin was used (Fig. 5). Selection of polyclonal antibodies was dictated by the fact that they allow identifying more different epitopes [19]. This fact is particularly important when analysing protein hydrolysates, because during digestion changes in the conformation of the protein may occur, which may result in a new epitopes formation.

The results obtained during SDS-PAGE separation of hydrolysates showed similarities between the studied species of lupin seed in the course of globulins proteolysis (Figs. 1). Therefore, in the following part of our studies we used only one variety of narrow-leaf and yellow lupin (Fig. 5a). Due to the fact that utilised antibodies were specific for $\gamma$-conglutin enzymes used in this part of our studies : pancreatin, trypsin and chymotrypsin. $\gamma$-Conglutin fraction isolated from narrow-leaf and yellow lupin seeds was used as the standard (Fig. 5a). Analysis of the membrane after incubation showed the presence of protein bands bonded with IgG antibodies specific for $\gamma$-conglutin (Fig. 5b). Narrow-leaf lupin hydrolysates exhibit immunoreactive properties, which were expected only in case of yellow lupin hydrolysates. The number of proteins reacting with the antibodies was different and depended on the specific activity of the enzyme used for the hydrolysis. For samples digested with chymotrypsin, low content of small bands corresponding to proteins characterised by molecular weights ranging from $36 \mathrm{kDa}$ to $10 \mathrm{kDa}$ was observed (Fig. 5b, lane 1). The hydrolysates obtained by the activity 


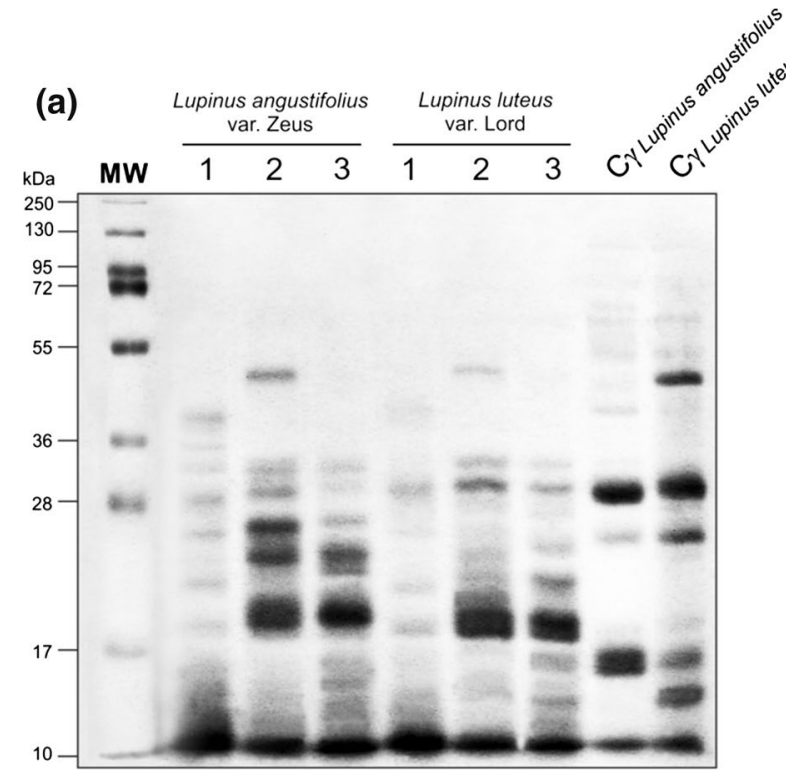

Fig. 5 Immunoblotting of lupin seed globulins samples after hydrolysis. a Electrophoretic separation of lupin seed globulins after digestion by: 1 chymotrypsin, 2 trypsin, and 3 pancreatin. b The immunoblotting membrane obtained for lupin seed globulins digestion products. Immunodetection was performed using specific antibodies

of pancreatin and trypsin had a similar profile of protein bands reactive to used antibodies (Fig. 5b, lanes 2, 3). In these samples, it was proved that the most immunoreactive proteins had proteins with molecular weights of $\sim 45 \mathrm{kDa}$, $31.4 \mathrm{kDa}$ and $16.5 \mathrm{kDa}$. The presence of these proteins is characteristic for the hydrolysate obtained after digestion with pancreatin and trypsin (Fig. 1, line 3; Fig. 5a, lanes $2,3)$. The molecular weights of these proteins correspond to the monomer and subunits $\alpha$ and $\beta \gamma$-conglutin, respectively $[23,25,27]$. The similarity in terms of immunoreactive properties observed between the studied species of lupin seeds after digestion proves high homology between their proteins. Based on immunoblotting results, it was found that proteins remaining after the hydrolysis retain their antigenic properties (Fig. 5b). The ability to bind specific antibodies is especially important for the allergenicity of lupin seeds. The main IgE-binding proteins of lupin have molecular weights in the range from 70 to $60 \mathrm{kDa}$ and $40 \mathrm{kDa}$ ( $\beta$-conglutin) [21], 30 and $17 \mathrm{kDa}(\gamma$-conglutin) [20] and $20 \mathrm{kDa}$ (basic subunit of $\alpha$-conglutin) [20]. Serious health risk associated with food allergy is the presence of cross-reactions, which in the case of lupin most often occurs with other legumes $[18,19]$. The reason for this phenomenon is the presence of identical or similar in terms of conformational epitopes within different proteins [44]. Hefle et al. [9] reported the occurrence of hives and swelling of the lymph nodes in patients who are allergic to peanuts after consuming pasta enriched with lupin flour. Using (b)

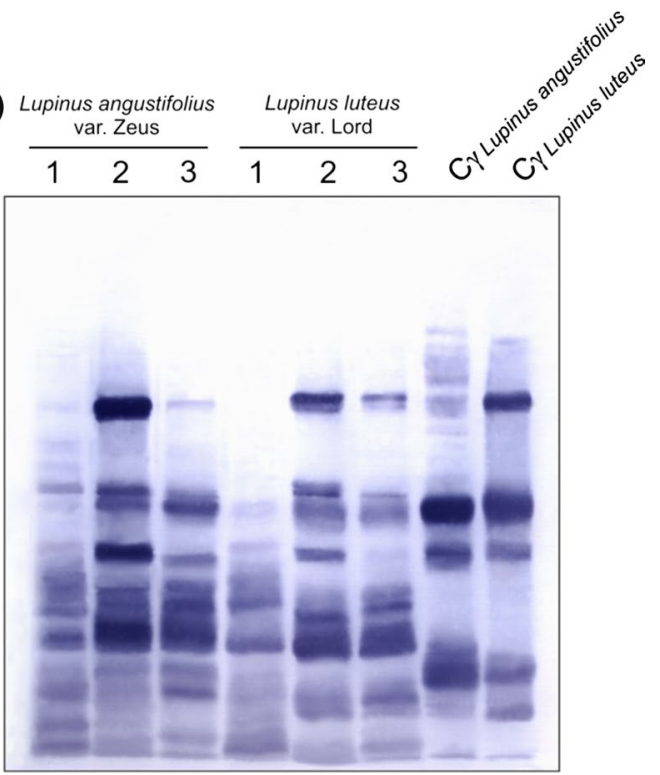

against yellow lupin (L. luteus) $\gamma$-conglutin. $\gamma$-Conglutin $(C \gamma)$ fractions isolated narrow-leaf ( $L$. angustifolius) and yellow ( $L$. luteus) lupin seeds were used as a standard during immunodetection. $M W$ molecular weight marker

the serum obtained from these patients, they found that the major proteins responsible for these reactions are characterised by molecular masses of 21,55 and $35 \mathrm{kDa}$. At the same time, Leduc et al. [45] showed that for the occurrence of cross-reactivity of the protein corresponded to molecular weights in the range $45-43 \mathrm{kDa}$ (by them is most immunoreactive) and $65 \mathrm{kDa}$. The observed cross-reactions may be due to the fact that the fraction of $\beta$-conglutin lupin, within which described above proteins occurred, has a high sequence identity with major peanut allergen Ara h 1 [46].

\section{Bioinformatic analyses of lupin seed globulins enzymatic hydrolysis}

The theoretical susceptibility of individual lupin seed globulins fractions ( $\alpha$-, $\beta$ - and $\gamma$-conglutins) to trypsin, chymotrypsin and pepsin digestion was analysed by PeptideCutter server (http://web.expasy.org/peptide_cutter/) (Tables 1, 2 ). Obtained results indicate that in the case of $\alpha$ - and $\beta$-conglutins the number of cleavage sites was very similar between compared enzymes. In details, when trypsin, chymotrypsin and pepsin are beaning used for digestion of $\alpha$ - and $\beta$-conglutins, an average theoretical cleavage sites were estimated as 80, 93 and 100, respectively (Table 1). When analysing $\gamma$-conglutin sequence by chymotrypsin and pepsin specificity, 97 and 124 potential numbers of cleavages are possible, respectively. Moreover, majority of these cleavage position sites during digestion are similar. 
Table 1 Theoretical analysis of narrow-leaf (L. angustifolius) $\alpha$ - and $\beta$-conglutin sequences in terms of hydrolysis susceptibility

\begin{tabular}{|c|c|c|c|c|c|}
\hline \multirow[t]{2}{*}{ Conglutin fraction } & \multirow[t]{2}{*}{ NCBI accession number } & \multirow[t]{2}{*}{ Number of amino acid residues in sequence } & \multicolumn{3}{|c|}{ Number of cleavages } \\
\hline & & & Trypsin & Chymotrypsin & Pepsin \\
\hline$\alpha$-conglutin 1 & gil328684559 & 506 & 45 & 97 & 105 \\
\hline$\alpha$-conglutin 2 & gil328684561 & 643 & 79 & 89 & 99 \\
\hline$\alpha$-conglutin 3 & gil328684563 & 585 & 64 & 94 & 96 \\
\hline$\beta$-conglutin 1 & gil328684565 & 611 & 89 & 95 & 104 \\
\hline$\beta$-conglutin 2 & gil328684567 & 603 & 85 & 92 & 99 \\
\hline$\beta$-conglutin 3 & gil328684569 & 580 & 78 & 94 & 99 \\
\hline$\beta$-conglutin 4 & gil328684571 & 590 & 85 & 91 & 98 \\
\hline$\beta$-conglutin 5 & gil328684573 & 637 & 99 & 94 & 97 \\
\hline$\beta$-conglutin 6 & gil328684575 & 593 & 88 & 95 & 102 \\
\hline$\beta$-conglutin 7 & gil328684577 & 605 & 93 & 92 & 96 \\
\hline
\end{tabular}

Table 2 Theoretical analysis of narrow-leaf (L. angustifolius) $\gamma$-conglutin sequence (NCBI accession number: gil328684579; 417 amino acid residues) in terms of hydrolysis susceptibility

\begin{tabular}{|c|c|c|}
\hline Enzyme & Number of cleavages & $\begin{array}{l}\text { Cleavages position }{ }^{\mathrm{a}} \\
\text { (amino acid number) }\end{array}$ \\
\hline Trypsin & 25 & $\begin{array}{l}34,35,50,77,132,138,154,184,185,193,234,246,249,256,305,310,322,323,337,343,370,391 \text {, } \\
\quad 393,402,406\end{array}$ \\
\hline Chymotrypsin & 97 & $\begin{array}{l}\mathbf{1}, \mathbf{2}, 3, \mathbf{1 4}, \mathbf{1 5}, \mathbf{2 7}, \mathbf{2 9}, 33,38,39,43, \mathbf{4 4}, \mathbf{4 5}, \mathbf{4 7}, \mathbf{5 1}, \mathbf{5 2}, 53, \mathbf{5 9}, \mathbf{6 0}, \mathbf{6 5}, \mathbf{6 9}, 71,81, \mathbf{8 4}, 97, \mathbf{1 0 3}, \mathbf{1 0 4}, \mathbf{1 1 5} \\
\mathbf{1 1 8}, \mathbf{1 2 3}, 126,129,133,136, \mathbf{1 4 2}, \mathbf{1 4 3}, \mathbf{1 4 4}, \mathbf{1 5 0}, \mathbf{1 5 1}, \mathbf{1 6 4}, \mathbf{1 6 6}, \mathbf{1 7 3}, \mathbf{1 7 7}, \mathbf{1 7 8}, \mathbf{1 8 0}, \mathbf{1 8 1}, \mathbf{1 8 3}, 187 \\
\mathbf{1 9 1}, \mathbf{1 9 4}, \mathbf{2 0 2}, \mathbf{2 0 3}, \mathbf{2 1 4}, 216, \mathbf{2 1 9}, \mathbf{2 2 2}, 225,227,230, \mathbf{2 3 8}, \mathbf{2 3 9}, \mathbf{2 5 0}, 251,259, \mathbf{2 6 7}, 268, \mathbf{2 7 7}, 284 \\
\mathbf{2 8 7}, 289, \mathbf{2 9 2}, \mathbf{2 9 5}, \mathbf{2 9 9}, 315,317,319, \mathbf{3 3 3}, 335, \mathbf{3 4 2}, \mathbf{3 4 9}, 350, \mathbf{3 6 0}, \mathbf{3 6 2}, 368, \mathbf{3 7 5}, 378, \mathbf{3 7 9}, 380 \\
\mathbf{3 8 4}, \mathbf{3 8 7}, \mathbf{3 8 9}, \mathbf{3 9 6}, \mathbf{4 0 1}, 404, \mathbf{4 1 1}, \mathbf{4 1 2}, \mathbf{4 1 4}\end{array}$ \\
\hline Pepsin & 124 & $\begin{array}{l}\mathbf{1}, \mathbf{2}, \mathbf{1 4}, \mathbf{1 5}, 17,26, \mathbf{2 7}, 28, \mathbf{2 9}, 42, \mathbf{4 4}, \mathbf{4 5}, 46, \mathbf{4 7}, \mathbf{5 1}, \mathbf{5 9}, \mathbf{6 0}, 64, \mathbf{6 5}, 68, \mathbf{8 4}, 102, \mathbf{1 0 3}, \mathbf{1 0 4}, 114, \mathbf{1 1 5}, 117, \\
\mathbf{1 1 8}, 122, \mathbf{1 2 3}, 132, \mathbf{1 4 2}, \mathbf{1 4 3}, \mathbf{1 4 4}, \mathbf{1 5 0}, \mathbf{1 5 1}, 163, \mathbf{1 6 4}, 165, \mathbf{1 6 6}, 172, \mathbf{1 7 3}, 176, \mathbf{1 7 7}, \mathbf{1 7 8}, \mathbf{1 8 0}, \mathbf{1 8 1}, \\
\mathbf{1 8 3}, 190, \mathbf{1 9 1}, \mathbf{1 9 4}, 201, \mathbf{2 0 2}, \mathbf{2 0 3}, 213, \mathbf{2 1 4}, \mathbf{2 1 9}, 221, \mathbf{2 2 2}, 224,226,229,237, \mathbf{2 3 8}, \mathbf{2 3 9}, \mathbf{2 5 0}, 266, \\
\mathbf{2 6 7}, 276,277,283,286, \mathbf{2 8 7}, \mathbf{2 9 2}, 294, \mathbf{2 9 5}, 298, \mathbf{2 9 9}, 314,316,317,318,319,332, \mathbf{3 3 3}, 334, \mathbf{3 3 5}, \\
341, \mathbf{3 4 2}, 348, \mathbf{3 4 9}, 359, \mathbf{3 6 0}, 361, \mathbf{3 6 2}, 374, \mathbf{3 7 5}, \mathbf{3 7 9}, 383, \mathbf{3 8 4}, 386, \mathbf{3 8 7}, 388, \mathbf{3 8 9}, \mathbf{3 9 6}, 400, \mathbf{4 0 1}, \\
403,410, \mathbf{4 1 1}, \mathbf{4 1 2}, 413, \mathbf{4 1 4}\end{array}$ \\
\hline
\end{tabular}

${ }^{\text {a }}$ Identical amino acid positions are indicated on bold

Surprisingly, while analysing $\gamma$-conglutin sequence in terms of hydrolysis susceptibility of trypsin, only 25 cleavage sites were found (Table 2). Complete hydrolysis of lupin seed globulins was observed when chymotrypsin was used for digestion (Fig. 5a, line 1). These results were very similar to those obtained during pepsin digestion of lupin seed globulins (Fig. 1, line 2). Similarity in terms of hydrolytic activity between these two enzymes may be explained by similarities in their specificity. These two enzymes preferentially hydrolyse a peptide bond on the carboxyl side of tyrosine, tryptophan or phenylalanine [34]. It is worth noting that these two enzymes lead to complete hydrolysis not only $\alpha$ - and $\beta$-conglutins but also $\gamma$-conglutin (Fig. 1, line 2; Fig. 5a, line 1). $\gamma$-Conglutin is a unique lupin seed protein fraction which undergoes $\mathrm{pH}$-dependent oligomerisation from monomer at $\mathrm{pH}<4.5$ (pepsin activity) to hexamer at $\mathrm{pH}>7.0$ (chymotrypsin activity) [27, 47]. Trypsin hydrolyses a peptide bond on the carboxyl side of lysine or arginine [34]. When this enzyme was used, similar results to pancreatin-treated lupin seed globulins were observed in SDS-PAGE separations (Fig. 1, line 3; Fig. 5a, line 2). Observed similarities were due to the fact that pancreatin is a mixture of several digestion enzymes where, among proteases, trypsin is the main one [35]. While analysing samples where pancreatin and trypsin were used, it was proved that $\gamma$-conglutin remains after digestion, while $\alpha$ and $\beta$-conglutins were completely hydrolysed (Fig. 1, line 3; Fig. 5a, line 2).

The hydrolysis of the protein substrate occurs only when a polypeptide chain can be attached to a specific stereochemical active site of a protease [48]. It is not possible that this place can attach to each of the secondary structural elements formed by $8-10$ amino acid residues present in globular proteins. Therefore, appropriate mechanisms are 
Fig. 6 The side view on the monomer surface of narrow-leaf (L. angustifolius) $\gamma$-conglutin (PDB accession number: $4 \mathrm{pph}$ ) with selected amino acid residues specific for hydrolytic activity of trypsin. Lysine and arginine residues are marked in red and green, respectively

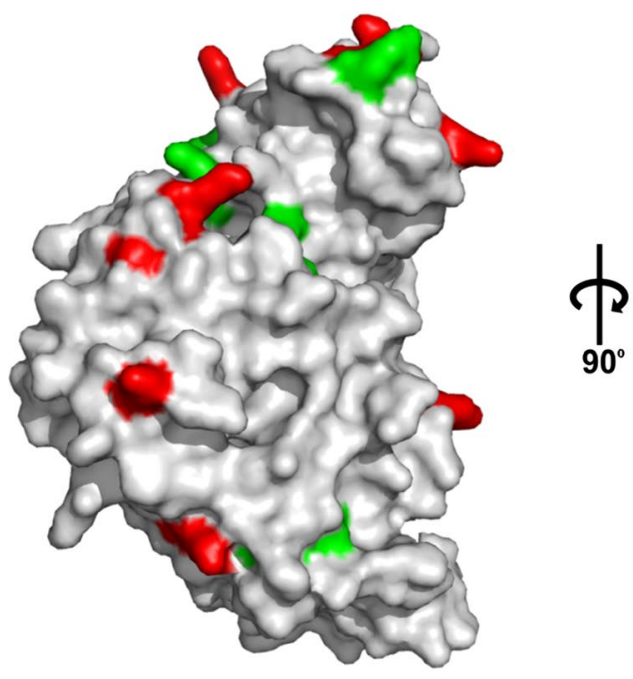

required to adjust the protein substrate to the active site of the enzyme to form a transition state which is essential for hydrolysis reaction. It is believed that the globular proteins in the native form are susceptible to enzymatic hydrolysis in limited degree [49]. $\gamma$-Conglutin at $\mathrm{pH} 7.5$ has the native conformation of the hexamer [27]. Under these conditions, $\gamma$-conglutin is resistant to trypsin, but chymotrypsin effectively carries out hydrolysis (Fig. 5a; Table 2). As already stated, a limited degree of hydrolysis with trypsin may arise from both interactions of the protein with flavonoids (Fig. 3), and the relatively small amount of theoretical proteolysis sites (Table 2). The arrangement of 25 amino acids residues at which trypsin should carry out the hydrolysis of a peptide bond in the $\gamma$-conglutin monomer is presented in Fig. 6.

Some of these amino acid residues, despite the location on the surface of the protein, are involved in the formation of $\alpha$ and $3_{10}$ helices (Arg77, Arg322, Lys323, Lys337, and Lys402), or $\beta$ chains (Lys 34, Lys132, Lys138, Arg246, Arg343 and Arg393). There are 14 amino acids not involved in formation of secondary structures elements and therefore theoretically available for the enzyme (Arg35, Lys50, Lys154, Lys184, Arg185, Arg193, Lys234, Lys249, Lys256, Lys305, Lys310, Arg370, Arg391 and Lys406). Thus, the additional resistance of $\gamma$-conglutin to the trypsin action can be explained by a relatively small amount of amino acid residues, at which hydrolysis should occur.

\section{Conclusions}

The electrophoretic separation of hydrolysed lupin seed globulins from narrow-leaf and yellow showed that pancreatin and trypsin, because of their high specificity, do not hydrolyse all proteins. $\gamma$-Conglutin turned out to be the fraction which is insensitive to pancreatin and trypsin action and at the same time retains its antigenic properties after digestion. In contrast, digestion carried out by pepsin, double digestion model and chymotrypsin results in complete degradation of globulins isolated from analysed lupin seeds species. Based on RP-HPLC chromatographic separations characteristic peptide profiles, specific for the enzyme used, were found. It was proved that lupin seed globulins might form the native complexes with phenolic compounds which can affect their digestion susceptibility, for example, it was observed in case of $\gamma$-conglutin. Additionally, $\gamma$-conglutin pancreatin and trypsin insensitivity can be also related with the fact that there are relatively a low number of cleavage sites specific for these enzymes which can be found within this protein fraction.

Funding This study was financed by the Ministry of Education and Science, Poland, under Project No. N N321 493340.

\section{Compliance with ethical standards}

Conflict of interest None.

Compliance with Ethics Requirements This article does not contain any studies with human or animal subjects.

Open Access This article is distributed under the terms of the Creative Commons Attribution 4.0 International License (http://creativecommons.org/licenses/by/4.0/), which permits unrestricted use, distribution, and reproduction in any medium, provided you give appropriate credit to the original author(s) and the source, provide a link to the Creative Commons license, and indicate if changes were made.

\section{References}

1. Terruzzi I, Senesi P, Magni P, Montesano A, Scarafoni A, Luzi L, Duranti M (2011) Nutr Metab Cardiovasc Dis 21:197-205

2. Lovati RM, Manzoni C, Castiglioni S, Parolari A, Magni C, Duranti M (2012) Br J Nutr 107:67-73 
3. Vargas-Guerrero B, Gracía-López PM, Martínez-Ayala AL, Domínguez-Rosales JA, Gurrola-Díaz CM (2014) Plant Food Hum Nutr 69:241-247

4. Capraro J, Magni C, Faoro F, Maffi D, Scarafoni A, Tedeschi G, Maffioli E, Parolari A, Lovati MR, Duranti M (2013) Biochem Biophys Res Commun 437:648-652

5. Sirtori CR, Lovati MR, Manzoni C, Castiglioni S, Duranti M, Magni C, Morandi S, D’Agostina A, Arnoldi A (2014) J Nutr 134:18-23

6. Directive 2006/142/EC amending Annex IIIa of Directive 2000/13/EC listing the ingredients which must under all circumstances appear on the labelling of food stuffs: OJ L 368, 23 December 2006

7. Romano C, Ferrara A, Tarallos S (1997) Allergy 52:113-114

8. Moreno-Ancillo A, Gil-Adrados AC, Dominguez-Noche C, Cosmes PM (2005) Pediatr Allergy Immunol 16:542-544

9. Hefle SL, Lemanske RF, Bush RK (1994) J Allergy Clin Immunol 94:167-172

10. Moneret-Vautrin DA, Guerin L, Kanny G, Flabbee J, Fremont S, Morisset M (1999) J Allergy Clin Immunol 104:883-888

11. Smith WB, Gillis D, Kette FE (2004) Med J Aust 181:219-220

12. Fæste CK (2010) In: Popping B, Diaz-Amigo C, Hoenieke K (eds) Molecular biological and immunological techniques and applications for food chemists. Wiley, New York

13. Novembre E, Moriondo M, Bernadini R, Azzari C, Rossi ME, Vierucci A (1999) J Allergy Clin Immunol 103:1214-1216

14. Holden L, Sletten GBG, Lindvik H, Fæste CK, Dooper MMBW (2008) Intern Archiv Allergy Immunol 146:267-276

15. Álvarez-Álvarez J, Guillamon E, Crespo J, Cuadrado C, Burbano C, Rodriguez J, Fernandez C, Muzquiz M (2005) J Agric Food Chem 53:1294-1298

16. Quaresma RR, Viseu R, Martins LM, Tomaz E, Inacio F (2007) Allergy 62:1473-1474

17. Peeters KA, Nordlee JA, Penninks AH, Chen L, Goodman RE, Bruijnzeel-Koomen CAFM, Hefle SL, Taylor SL, Knulst AC (2007) J Allergy Clin Immunol 120:647-653

18. Ballabio C, Magni C, Restani P, Mottini M, Fiocchi A, Tedeschi G, Duranti M (2010) Plant Food Hum Nutr 65:396-402

19. Magni C, Ballabio C, Restani P, Sironi E, Scarafoni A, Poiesi C, Duranti M (2005) J Agric Food Chem 53:2275-2281

20. Magni C, Herndl A, Sironi E, Scarafoni A, Ballabio C, Restani P, Bernardini R, Novembre E, Vierucci A, Duranti M (2005) J Agric Food Chem 53:4567-4571

21. Goggin DE, Mir G, Smith WB, Stuckey M, Smith PMC (2008) J Agric Food Chem 56:6370-6377

22. Ballabio C, Penas E, Uberti F, Fiocchi A, Duranti M, Magni C, Restatni P (2013) Pediat Allergy Immunol 24:270-275

23. Czubinski J, Dwiecki K, Siger A, Kachlicki P, Neunert G, Lampart-Szczapa E, Nogala-Kalucka M (2012) J Agric Food Chem 60:1830-1836
24. Bradford M (1976) Anal Biochem 72:248-254

25. Czubiński J, Dwiecki K, Siger A, Neunert G, Lampart-Szczapa E (2014) Food Chem 143:418-426

26. Laemmli UK (1970) Nature 227:680-685

27. Czubinski J, Barciszewski J, Gilski M, Szpotkowski J, Debski J, Lampart-Szczapa E, Jaskolski M (2015) Acta Crystallogr D71:224-238

28. Gasteiger E, Hoogland C, Gattiker A, Duvaud S, Wilkins MR, Appel RD, Bairoch A (2005) In: Walker JM (ed) The proteomics protocols handbook. Humana Press, New York

29. Kabsch W, Sander C (1983) Biopolymers 22:2577-2637

30. Duranti M, Consonni A, Magni C, Sessa F, Scarafoni A (2008) Trend Food Sci Technol 19:624-633

31. Freitas RL, Teixeira AR, Ferreira RB (2007) Food Chem 102:323-329

32. Capraro J, Magni C, Scarafoni A, Duranti M (2009) J Agric Food Chem 57:8612-8616

33. Aguilar MI (2004) In: Aguilar MI (ed) HPLC of peptides and proteins. Humana Press, New Jersey

34. Keil B (1992) Specificity of proteolysis. Springer, Berlin

35. Whitcomb DC, Lowe ME (2007) Dig Dis Sci 52:1-17

36. Sosulski F, Dabrowski K (1984) J Agric Food Chem 32:131-133

37. Lampart-Szczapa E, Siger A, Trojanowska K, Nogala-Kałucka M, Małecka M, Pachołek B (2003) Nahrung/Food 47:286-290

38. Dueñas M, Hernandez T, Estrella I, Fernandez D (2009) Food Chem 117:599-607

39. Siger A, Czubinski J, Kachlicki P, Dwiecki K, Lampart-Szczapa E, Nogala-Kałucka M (2012) J Food Compos Anal 25:190-197

40. Kroll J, Rawel HM, Rohn S (2003) Food Sci Technol Res 9:205-218

41. Ozdal T, Capanoglu E, Altay F (2013) Food Res Int 51:954-970

42. Gonzales GB, Smagghe G, Grootaert Ch, Zotti M, Raes K, Van Camp J (2015) Drug Metab Rev. 47(2):175-190

43. Łoza A, Lampart-Szczapa E (2008) Pol J Food Nutr Sci 58:283-287

44. Szymkiewicz A, Jędrychowski L (2005) Acta Aliment 34:295-306

45. Leduc V, Moneret-Vautrin DA, Guerin L (2002) Allerg Immunol 34:213-217

46. Guarneri F, Guarneri C, Benvenga S (2005) Int Arch Allergy Immunol 138:273-277

47. Capraro J, Spotti P, Magni C, Scarafoni A, Duranti M (2010) Int J Biol Macromol 47:502-507

48. Schechter I, Berger A (1967) Biochem Biophys Res Commun 27:157

49. Fontana A, De Laureto P, Spolaore B, Frare E, Picotti P, Zambonin M (2004) Acta Biochim Pol 51:299-321 